\title{
Prevention and Control of COVID-19 Risks for Long-Term Care Facilities Based on the Prospect Theory
}

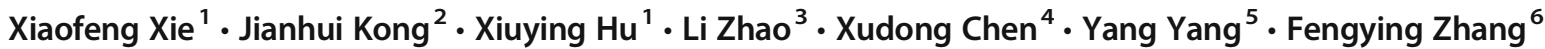

Accepted: 16 May 2021 / Published online: 14 August 2021

(C) The Author(s), under exclusive licence to Springer Science+Business Media, LLC, part of Springer Nature 2021

\begin{abstract}
Given the complexity and uncertainty of the current COVID-19 risks, the elderly people in long-term care facilities are at the highest risk for infection. In order to study the prevention and control strategies of COVID-19 risks in long-term care facilities, this paper uses the prospect theory to construct the decision-making model of COVID-19 risk behavior of long-term care facilities, analyses the risk behavior strategies of the caregivers and managers, and reveals the impact of risk management cost, risk loss and external supervision on the risk behavior decision-making of the caregivers and managers. Furthermore, from the perspective of long-term care facilities, this paper analyzes the constraints that enable it to achieve optimal risk management strategy. Combined with the simulation analysis, it is found that the decision of risk behavior of the caregivers and managers is positively related to the risk behavior choice, risk loss, and supervision. Then, only when the incentives set by the supervision are within a reasonable range can the caregivers and managers be motivated to take proactive risk management strategies. The study has important theoretical and practical significance for the management of COVID-19 risks in long-term care facilities.
\end{abstract}

Keywords Long-term care facilities $\cdot$ COVID-19 risk $\cdot$ Risk management $\cdot$ Decision-making $\cdot$ Prospect theory

\section{Introduction}

According to the statistics of the World Health Organization (WHO), as of August 27, 2020, 168 countries and regions around the world had reported confirmed cases of coronavirus disease 2019 (COVID-19), with a total of more than 24.0212 million cases and 820,000 deaths [1]. Currently, the known ways of COVID-19 transmission include human-to-human transmission, mainly through droplets and contact. A basic reproduction number of $3.6 \sim 4.0$, COVID-19 is an infectious

Fengying Zhang

zhangfengying@scu.edu.cn

1 West China Hospital/West China School of Nursing, Innovation Center of Nursing Research, Sichuan University, Chengdu, China

2 Law School, Southwest Minzu University, Chengdu, China

3 Department of Health Policy and Managemen, West China School of Public Health, Chengdu, China

4 College of Management Science, Chengdu University of Technology, Chengdu, China

5 School of Economics Mathematics, Southwestern University of Finance and Economics, Chengdu, China

6 West China School of Nursing/West China Hospital, Sichuan University, Chengdu, China disease with moderate to high infectivity $[2,3]$. The elderly people, who especially suffering with asthma, diabetes and heart disease are at increased risk for virus infection, with the elderly being the most susceptible to the novel coronavirus and the most likely to progress to severe illness $[4,5]$. In the context of COVID-19 pandemic, many countries have reported cases of cluster infection in the long-term care facilities [6]. According to an article on the website of The New York Times dated August 13, 2020, "At least 68,000 residents and workers have died from the coronavirus at nursing homes and other long-term care facilities for older adults in the United States, according to a New York Times database. As of August 13, the virus has infected more than 402,000 people at some 17,000 facilities." Moreover, deaths related to Covid19 in long-term care facilities accounted for more than $41 \%$ of the pandemic fatalities (The New York Times, 2020) [7]. The older people are, the more difficult it is for them to have COVID-19 treated in case of infection. Long-term care facilities take the responsibility of controlling the spread of COVID-19 and ensuring the physical and mental health of the elderly $[8,9]$.

The COVID-19 risks referred to in this paper are defined as the risk for the occurrence of COVID-19 among the elderly and caregivers that may cause illness, damage or death to the elderly due to improper prevention and control in long-term 
care facilities as well as incidents that may seriously affect the operation of long-term facilities. COVID-19 is characterized by suddenness, public coverage, severity, urgency, complexity and variability. Besides, it comes with high risk levels and serious consequences, and it is present throughout the work carried out in senior care facilities in the pandemic context. In fact, in the context of COVID-19 pandemic, any improper prevention and control may lead to COVID-19 risks and cluster infection in such facilities as community hospitals, clinics, home care settings, nursing homes and geracomium. And such incidents can be caused by factors such as facility management, caregivers' behaviour and environmental facilities. The risk for the occurrence of COVID-19 among the elderly and caregivers that may cause illness, damage or death to the elderly due to improper prevention and control in long-term care facilities as well as incidents that may seriously affect the operation of long-term care facilities [10]. And such incidents can be caused by factors such as facility management, caregivers' behaviour and environmental facilities [11-14]. The primary task of COVID-19 risk management is to identify high risks and coordinate the elimination and reduction of the occurrence of COVID-19 risk events. Achieving maximum safety at the lowest cost is the most scientific risk management method [15]. The key to COVID-19 risk management is to improve the risk awareness and response ability of caregivers in long-term care facilities. Using the risk system assessment scale, managers entered all relevant data such as the current management status and risk factors into the computer to establish the minimum data set for long-term care facilities [16, 17], so as to provide managers with information and decision-making support and improve the efficiency of COVID-19 risk management [18]. Using the MDS 2.0 assessment scale, Shaw et al. [19] analyzed the correlation between the occurrence of senior care risks and the characteristics of long-term care facilities, including management process and staffing, to prove the validity of the assessment system.

Through risk management, the risk of contracting COVID-19 in long-term care facilities was transformed, decomposed as well as effectively prevented and controlled to varying degrees $[20,21]$. Nevertheless, longterm care facilities suffer from a serious shortage of staff [22]. Specifically, the proportion of facility to the number of caregivers in private long-term facilities has been staying at somewhere between $1: 15$ and 1:20, far lower than the international standard of 1:4.5 in nursing homes [23]. To save costs, some long-term facilities recruit less staff and give them low salaries and a heavy workload, leading to an increased turnover rate [24]. Caregivers in long-term facilities have heavy daily tasks, which are repetitive and tedious and cause them high pressure [25]. As a result, caregivers generally have low willingness to work and low job satisfaction. In China, there is a serious shortage of professional senior caregivers, and the turnover rate of caregivers in undeveloped areas is as high as $20 \%$ [26-28]. Caregivers find it difficult to properly cater to the nursing needs of the elderly if they are dissatisfied with their jobs. Under the impact of COVID-19 pandemic in the world, the risk of being exposed to COVID-19 is even more obviously. As a result, there is an inevitable link between risk occurrence and the caregivers and managers' behaviour, which will pose even greater challenges to the long-term care facilities [29].

The prospect theory has made ground-breaking contributions to decision-making research in the context of uncertainty and is now widely applied in various decision-making analyse $[30,31]$. In the process of COVID-19 risk management in long-term care facilities, there are two types of groups, namely, long-term care facilities managers and caregivers. Due to the uncertainty and complexity of long-term care facilities compared to general community service centres, the managers and caregivers in long-term care facilities differ in such aspects as COVID-19 risk perception, risk management knowledge, and the abilities of analysing COVID-19 risk information, and effectively response for the situation. And they tend to exhibit characteristics of bounded rationality [32-34]. In reality, caregivers in long-term care facilities are often not completely rational and are susceptible to the influences of their surroundings and their psychological factors. The analysis of value according to the prospect theory is based on the change in the gain of managers and caregivers instead of the final state of the gain, and this change is defined according to the degree of deviation from the reference standard. So, managers and caregivers often determine their behaviour based on their perspectives or reference standards. As their reference standards differ, their expected "gain" or "loss" also differs.

Based on this, this paper introduces the prospect theory to analyse the evolution process and mechanism of the risk responses of COVID-19 risk management subjects in long-term care facilities. It also explains the reasons for the behavioural tendencies of different COVID-19 risk subjects and the conditions for the selection of COVID-19 risk management strategies from the perspective of risk perception theory. The main research contribution of this paper lies in provide theoretical and decision-making support for COVID-19 risk management in long-term care facilities by analysing the interrelationship between risk management behaviour and nursing behaviour under different conditions as well as the consequences of its evolution.

The structure of the rest of the paper is organized as follows. Section two sets up the decision-making model for COVID-19 risk response in long-term care facilities. In section three, the decision-making on risk responses is simulated and analyzed. Section four puts forward the risk management and control strategies based on the prospect theory. Last, section five concludes the study and proposes the directions for future research. 


\section{Decision-making model for COVID-19 risk response in long-term care facilities}

\subsection{Main factors influencing the risk response of the caregivers and the managers}

The risk response of caregivers and managers in long-term care facilities is related to the COVID-19 risk loss caused to long-term care facilities by risk management behaviour. Since the behaviour of caregivers and managers in long-term care facilities directly affect the intensity of the risk of COVID-19 infection among the elderly in these facilities, they also tend to significantly affect such risk loss as the loss of reputation and financial loss caused to long-term care facilities by the risk of COVID-19 infection.

Assume that facility caregivers can choose between "standard" and "non-standard" caregiving behaviour, and that facility managers can choose between "proactive" and "passive" risk management behaviour [22-25]. If the probability for the caregivers to choose "standard" caregiving behaviour is $P_{x}$, then the probability for them to choose "non-standard" caregiving behaviour is $1-P_{x}$. Similarly, if the probability for the managers to choose "proactive" risk management is $P_{y}$, then the probability for them to choose "passive" risk management is $1-P_{y}$. The gain the caregivers get for providing regular caregiving services is $E_{C}$, and the gain for the facility managers to carry out regular risk management is $E_{M}$. The cost the caregivers pay for choosing "standard" caregiving behaviour (reflecting the cost the caregivers incur for their increased efforts and more care time) is represented by $C_{C}$. The cost the facility managers pay for choosing "proactive" risk management behaviour (reflecting the cost the facility managers incur for such factors as their enhanced management ability, increased efforts and more management time) is represented by $C_{M}$. Therefore, $0<C_{C}<E_{C}$, $0<C_{M}<E_{M}$.

If the caregivers engage in "standard" caregiving behaviour and the managers engage in "proactive" risk management, the breakout of COVID-19 in long-term care facilities can be prevented, thereby preventing risk loss. Otherwise, long-term care facilities will suffer losses incurred by COVID-19 infection among elderly residents. Assume that the risk loss a long-term care facilities suffers when the caregivers engage in "non-standard" caregiving behaviour and the managers carry out passive risk management is $L$. In fact, the caregivers' "standard" caregiving behaviour and the managers' "proactive" risk management behaviour can both lower the infection rate of elderly residents in the long-term care facilities, thereby reducing relevant losses to the facility. $\gamma_{C}$ represents the discount factor of the risk loss incurred to long-term care facilities (referred to as "risk loss discount factor" below) by COVID-19 when the caregivers adopt "standard" caregiving behaviour, regardless of whether or not the managers engage in "proactive" risk management. In this case, the loss the long-term care facilities suffers is $\left(1-\gamma_{C}\right) L$, and $\gamma_{C} \in(0,1) . \gamma_{M}$ represents the risk loss discount factor by COVID-19 when the managers engage in "proactive" COVID-19 risk management, regardless of whether or not the caregivers choose "standard" caregiving behaviour. And in this case, the loss the long-term care facilities suffers is $\left(1-\gamma_{M}\right) L$, and $\gamma_{M} \in\left(0,1 . \gamma_{C}\right.$ measures the positive effect of the caregivers' "standard" caregiving behaviour on the risk loss incurred by COVID-19 in the facility, whereas $\gamma_{M}$ measures the positive effect of the managers' "proactive" risk manageemnt behaviour on the risk loss incurred by COVID-19 in the facility.

In essence, different risk responses cause long-term care facilities to face different discount rates of risk loss incurred by COVID-19 and reflect the intensity of COVID-19 infection among elderly people in long-term care facilities. In particular, $\gamma_{C}+\gamma_{M}=1$. In other words, if both the caregivers and the facility managers choose to proactively respond to COVID19 risks, effective risk management behaviour will prevent the long-term care facilities from suffering loss incurred by COVID-19 risks, at which point the risk discount rate reaches its maximum 1. Furthermore, assume that the risk loss suffered by a long-term care facilities is shared between its caregivers and managers. If $\beta$ refers to the proportion of risk loss incurred by COVID-19 borne by the caregivers, then $1-\beta$ refers to the proportion of risk loss incurred by COVID-19 borne by the facility managers, and $\beta \in(0,1)$.

To effectively regulate and encourage proactive COVID19 risk management in long-term care facilities, the government and industry regulators will introduce a strict punishment and reward mechanism. When the caregivers choose to engage in "non-standard" caregiving behaviour, they will be punished by the government and industry regulators, and the punishment the caregivers face is represented by $K_{C}$; when the caregivers choose to engage in "standard" caregiving behaviour, they will be rewarded by the government and industry regulators, and the reward the caregivers receive is represented by $S_{C}$. Similarly, when the facility managers choose "passive" risk management behaviour, they will be punished by the government and industry regulators, and the punishment the managers face is indicated by $K_{M}$; and when the facility managers choose to engage in "proactive" caregiving behaviour, they will be rewarded by the government and industry regulators, and the reward the facility managers receive is represented by $S_{M}$. Without loss of generality, this paper assumes that $S_{C}=K_{C}, S_{M}=K_{M}$.

The main factors influencing the risk responses of the caregivers and the managers and the consequences of such responses are indicated in Table 1 below. To distinguish between different participants and risk response strategies, this 
Table 1 The main factors influencing the risk responses of the caregivers and the managers and the consequences of such responses

\begin{tabular}{|c|c|c|c|c|}
\hline \multirow{2}{*}{$\begin{array}{l}\text { Both } \\
\text { parties to } \\
\text { the } \\
\text { process }\end{array}$} & \multirow{2}{*}{$\begin{array}{l}\text { Choice of risk } \\
\text { response }\end{array}$} & \multicolumn{3}{|c|}{ Main influencing factors } \\
\hline & & Gain & $\begin{array}{l}\text { Discount factor of } \\
\text { the loss incurred } \\
\text { to long-term care } \\
\text { facilities }\end{array}$ & $\begin{array}{l}\text { Punishment by } \\
\text { government } \\
\text { and industry } \\
\text { regulators }\end{array}$ \\
\hline \multirow[t]{3}{*}{ Caregivers } & $\begin{array}{l}\text { "Standard" } \\
\text { caregiving } \\
\text { behaviour } C_{1} \\
S_{C}\end{array}$ & $E_{C^{-}}^{-}$ & $C_{C}$ & $\gamma_{C}$ \\
\hline & $\begin{array}{l}\text { "Non-standard" } \\
\text { caregiving } \\
\text { behaviour } C_{2}\end{array}$ & $E_{C}$ & 0 & $-K_{C}$ \\
\hline & $\begin{array}{l}\text { Reference } \\
\text { standard }\end{array}$ & $T_{C 1}$ & $T_{C 2}$ & $T_{C 3}$ \\
\hline Weight & $W_{C 1}$ & $W_{C 2}$ & $W_{C 3}$ & \\
\hline \multirow[t]{3}{*}{ Managers } & $\begin{array}{l}\text { "Proactive risk } \\
\text { management } \\
\text { behaviour" } \\
M_{1} \\
S_{M}\end{array}$ & $E_{M^{-}}$ & $C_{M}$ & $\gamma_{M}$ \\
\hline & $\begin{array}{c}\text { "Passive" risk } \\
\text { management } \\
\text { behaviour } M_{2}\end{array}$ & $E_{M}$ & 0 & $-K_{M}$ \\
\hline & $\begin{array}{l}\text { Reference } \\
\text { standard }\end{array}$ & $T_{M 1}$ & $T_{M 2}$ & $T_{M 3}$ \\
\hline Weight & $W_{M 1}$ & $W_{M 2}$ & $W_{M 3}$ & \\
\hline
\end{tabular}

paper has respectively added subscripts $C$ and $M$ to the corresponding variables, namely, the caregivers and the facility managers, indicated the "standard" and "non-standard" caregiving behaviour of the caregivers as $C_{1}$ and $C_{2}$ respectively, and represented the facility managers' "proactive" and "passive" risk management behaviour by $M_{1}$ and $M_{2}$ respectively.

In this table, $T_{C 1}, T_{C 2}$ and $T_{C 3}$ respectively represent the set reference standards for the caregivers' gain, the discount factor of the loss incurred to the facilities by caregivers' risk response and the punishment on the caregivers by the government and industry regulators. $T_{M 1}, T_{M 2}, T_{M 3}$ respectively stand for the set reference standards for the facility managers' gain, the discount factor of the loss incurred to the facilities by the managers' risk response, and the punishment on the managers by the government and industry regulators. Thus, $T_{C}=$ $W_{C 1} T_{C 1}-W_{C 2} T_{C 2} L+W_{C 3} T_{C 3}$ is the weighted reference standard of caregivers' expected gain, while $T_{M}=W_{M 1} T_{M 1}-$ $W_{M 2} T_{M 2} L+W_{M 3} T_{M 3}$ is the weighted reference standard of managers' expected gain.

\subsection{The matrix of the risk responses of the caregivers and the managers}

As mentioned earlier, the risk response strategies of the caregivers and the managers in long-term care facilities are mainly influenced by three factors, namely, their own gain, external regulation and the decisions of internal stakeholders. Therefore, when analysing the prospective value of the strategies under the caregivers' different caregiving behaviour or the managers' different risk management behaviour, it is imperative to include the influence of the risk responses of the facility managers (or the caregivers) on their own gain.

First, the caregivers' net gain from different risk response strategies is analyzed. And the decision tree for the caregivers' caregiving behaviour is shown in Fig. 1. If caregivers choose "standard" caregiving behaviour $C_{1}$, the managers will be faced with two decisions: (1) When the managers choose "proactive" risk management behaviour $M_{1}$, the risk loss discount factor" below is $\gamma_{C}+\gamma_{M}=1$, and the net gain of the caregivers is $\pi_{C_{1},} M_{1}{ }^{C}=E_{C}-C_{C}-\left(1-\gamma_{C}-\gamma_{M}\right) L=E_{C}-C_{C}$. (2) When the managers choose "passive" risk management behaviour $M_{2}$, the risk loss discount factor is only $\gamma_{C}$, and the caregivers get the reward $K_{M}$ for engaging in "standard" caregiving behaviour. Therefore, the net gain of the caregivers is $\pi_{C_{1},} M_{2}{ }^{C}=E_{C}-C_{C}+K_{M}-\left(1-\gamma_{C}\right) \beta L$.

If the caregivers choose "non-standard" caregiving behaviour $C_{2}$, the managers will also be faced with two decisions: (1) When the managers choose "proactive" risk management behaviour $M_{1}$, the risk loss discount factor is $\gamma$, and the punishment imposed on the caregivers is $K_{C}$. So the net gain of the caregivers is $\pi_{C_{2},} M_{1}{ }^{C}=E_{C}-K_{C}-\left(1-\gamma_{M}\right) \beta L$; (2) When the managers choose "passive" risk management behaviour $M_{2}$, the risk loss discount factor is $L$, and the punishment imposed on the caregivers is $K_{C}$. So, the net gain of the caregivers is $\pi_{C_{2},} M_{2}{ }^{C}=E_{C}-K_{C}-\beta L$.

Similarly, the facility managers' net gain from different risk response strategies can also be analyzed. And the decision tree for the facility managers' caregiving behaviour is shown in Fig. 2. If the managers choose "proactive" risk management behaviour $M_{1}$, the caregivers will be faced with two decisions: (2) When the caregivers choose "standard" caregiving behaviour $C_{1}$, the risk loss discount factor is $\gamma_{C}+\gamma_{M}=1$, and the net gain of the managers is $\pi_{C_{1},} M_{1}{ }^{M}=E_{M}-C_{M}-\left(1-\gamma_{C}-\gamma_{M}\right)$ $L=E_{M}-C_{M}$. (2) When the caregivers choose "non-standard" caregiving behaviour $C_{2}$, the risk loss discount factor is only $\gamma_{M}$, and the managers receive the reward $K_{C}$ for engaging in proactive risk management behaviour. Therefore, the net gain of the managers is $\pi_{C_{2}}, M_{1}{ }^{M}=E_{M}-C_{M}+K_{M}-\left(1-\gamma_{M}\right)$ $(1-\beta) L$.

If the managers choose "passive" risk management behaviour $M_{2}$, the caregivers will also be faced with two decisions: (1) When the caregivers choose "standard" caregiving behaviour $C_{1}$, the risk loss discount factor is $\gamma_{C}$, and the punishment imposed on the managers is $K_{M}$. So the net gain of the managers is $\pi_{C_{1},} M_{2}{ }^{M}=E_{M}-K_{M}-\left(1-\gamma_{C}\right)(1-\beta) L$; (2) When the caregivers choose the "non-standard" risk 
Fig. 1 Decision tree of the caregivers' behaviour

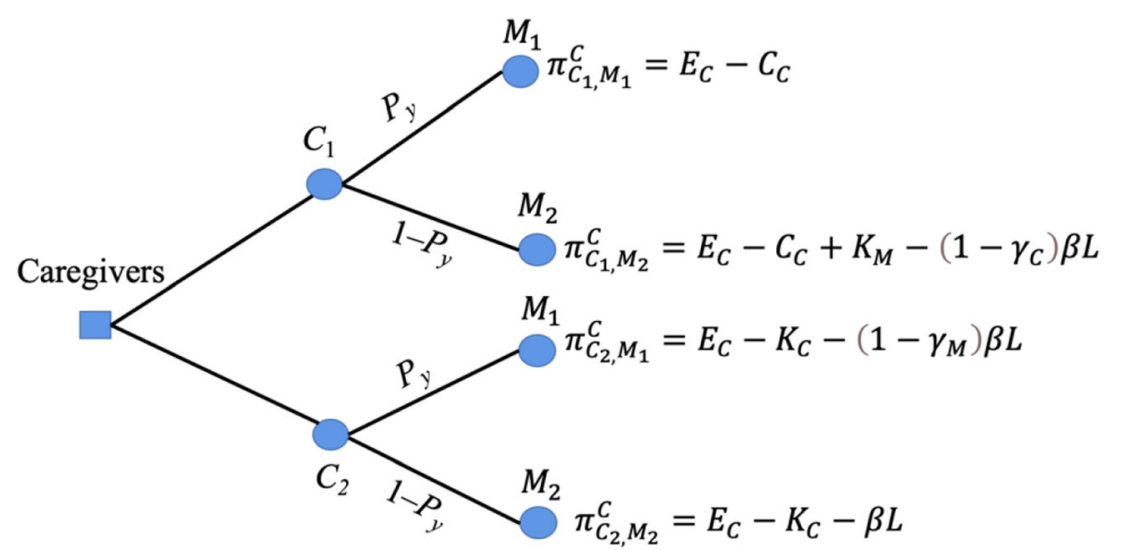

management behaviour $C_{2}$, the risk loss discount factor is $L$, and the punishment imposed on the managers is $K_{M}$. So net gain of the managers is $\pi_{C_{2},} M_{2}{ }^{M}=E_{M}-K_{M}-(1-\beta) L$.

To sum up, the matrix of the risk responses of the caregivers and the managers is indicated in Table 2 below. The strategies for the caregivers are "standard" caregiving behaviour $C_{1}$ or "non-standard" caregiving behaviour $C_{2}$. And the strategies for the managers are "proactive" risk management behaviour $M_{1}$ or the "passive" risk management $M_{2}$. For long-term care facilities, there are four strategy profiles for the caregivers and managers, namely, $\left(C_{1}, M_{1}\right),\left(C_{1}, M_{2}\right),\left(C_{2}, M_{1}\right),\left(C_{2}, M_{2}\right)$.

Next, the decision-making models for the different risk responses of the caregivers and the managers are established respectively. And the optimal strategies will be formulated by comparing the prospective value of their gain from different risk responses. On this basis, the influences of factors such as the stakeholders' behaviour, risk management cost, risk loss and external regulation on the two parties' risk response decisions are discussed. Finally, the constraints for the caregivers and the managers to achieve the optimal risk management strategies are analyzed from the perspective of long-term care facilities.

\subsection{The decision-making model for the caregivers' risk responses}

According to caregivers' gain from different risk responses and the corresponding prospective value, the prospective value of the caregivers' choice of "standard" caregiving behaviour $C_{1}$ can be arrived at as follows:

$$
\begin{aligned}
V\left(C_{1}\right)= & W\left(P_{y}\right) V\left(\pi_{C_{1}, M_{1}}^{C}-T_{C}\right) \\
& +W\left(1-P_{y}\right) V\left(\pi_{C_{1}, M_{2}}^{C}-T_{C}\right) \\
= & W\left(P_{y}\right) V\left(E_{C}-C_{C}-T_{C}\right) \\
& +W\left(1-P_{y}\right) V\left(E_{C}-C_{C}+K_{M}-\left(1-\gamma_{C}\right) \beta L-T_{C}\right)
\end{aligned}
$$

And the prospective value of the caregivers' choice of "non-standard" caregiving behaviour $C_{2}$ is:

$$
\begin{aligned}
V\left(C_{2}\right)= & W\left(P_{y}\right) V\left(\pi_{C_{2}, M_{1}}^{C}-T_{C}\right) \\
& +W\left(1-P_{y}\right) V\left(\pi_{C_{2}, M_{2}}^{C}-T_{C}\right) \\
= & W\left(P_{y}\right) V\left(E_{C}-C_{C}-\left(1-\gamma_{M}\right) \beta L-T_{C}\right) \\
& +W\left(1-P_{y}\right) V\left(E_{C}-K_{C}-\beta L-T_{C}\right)
\end{aligned}
$$

Fig. 2 Decision tree of the managers' risk management behaviour

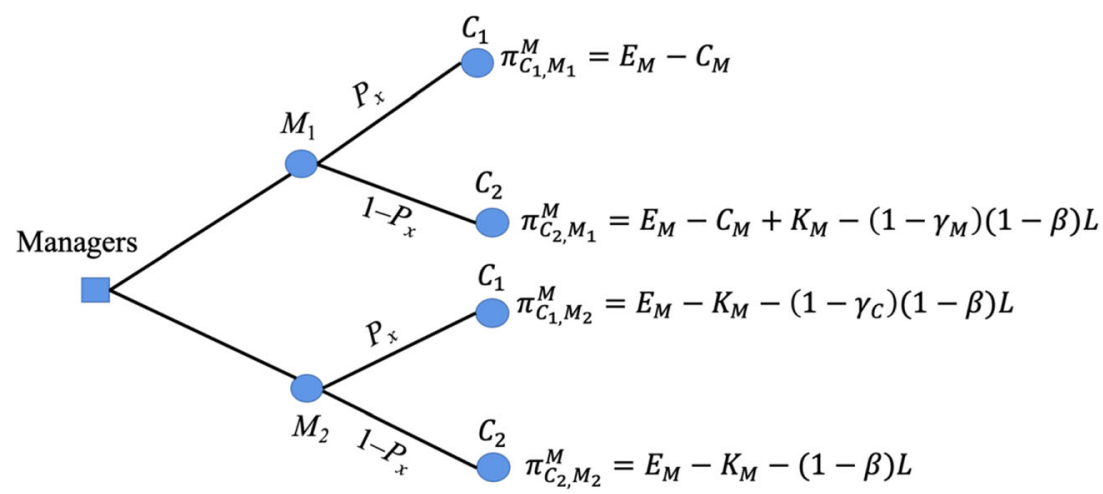


Table 2 Matrix for the risk responses of the caregivers and the managers

\begin{tabular}{|c|c|c|}
\hline \multirow[t]{2}{*}{ Caregivers $(C)$} & \multicolumn{2}{|l|}{ Facility managers $(M)$} \\
\hline & $\begin{array}{l}\text { "Proactive" risk management } \\
\text { behaviour } M_{1}\end{array}$ & "Passive" risk management behaviour $M_{2}$ \\
\hline "Standard" caregiving behaviour $C_{1}$ & $\begin{array}{l}\pi_{C_{1},} M_{1}^{C}=E_{C}-C_{C} \\
\pi_{C_{1},} M_{1}^{M}=E_{M}-C_{M}\end{array}$ & $\begin{array}{l}\pi_{C_{1},} M_{2}{ }^{C}=E_{C}-C_{C}+K_{M}-\left(1-\gamma_{C}\right) \beta L \\
\pi_{C_{1},} M_{2}{ }^{M}=E_{M}-K_{M}-\left(1-\gamma_{C}\right)(1-\beta) L\end{array}$ \\
\hline "Non-standard" caregiving behaviour $C_{2}$ & $\begin{array}{l}\pi_{C_{2,}} M_{1}{ }^{C}=E_{C}-K_{C}-\left(1-\gamma_{M}\right) \beta L \\
\pi_{C_{2},} M_{1}{ }^{M}=E_{M}-C_{M}+K_{C}-\left(1-\gamma_{M}\right)(1-\beta)\end{array}$ & $\begin{array}{l}\pi_{C_{2},} M_{2}{ }^{C}=E_{C}-K_{C}-\beta L \\
\pi_{C_{2},} M_{2}{ }^{M}=E_{M}-K_{M}-(1-\beta) L\end{array}$ \\
\hline
\end{tabular}

$\Delta V_{C}$, the deviation of the prospective value of the caregivers' different caregiving behaviour, is:

$$
\begin{aligned}
\Delta V_{C}=V\left(C_{1}\right)-V\left(C_{2}\right)= & W\left(P_{y}\right)\left[V\left(E_{C}-C_{C}-T_{C}\right)-V\left(E_{C}-C_{C}-\left(1-\gamma_{M}\right) \beta L-T_{C}\right)\right] \\
& +W\left(1-P_{y}\right)\left[V\left(E_{C}-C_{C}+K_{M}-\left(1-\gamma_{C}\right) \beta L-T_{C}\right)-V\left(E_{C}-K_{C}-\beta L-T_{C}\right)\right]
\end{aligned}
$$

Specifically, with reference to Gonzalez and Wu's $(1996,1999)[34,35]$ setting of weight functions, assume that $W(x)={\frac{x^{k}}{(1-x)}}^{k}+x^{k}, 0<k<1$. If $\pi_{C_{i,}} M_{j}{ }^{C}-T_{C}>0$, then the prospective value $V\left(\pi_{C_{i}}, M_{j}{ }^{C}\right)=\left(\pi_{C_{i}} M_{j}{ }^{C}-T_{C}\right)^{\alpha}$; and if $\pi_{C_{i}}, M_{j}{ }^{C}-T_{C} \leq 0$, then the prospective value $V\left(\pi_{C_{i,}} M_{j}{ }^{C}\right)$ $=-\lambda\left(-\pi_{C_{i,}} M_{j}{ }^{C}+T_{C}\right)^{\beta}$, and $i, j \in\{1,2\}$. Specifically, 0 $<\alpha, \beta<1, \lambda>1, V^{\prime(x)}>0, \alpha$ and $\beta$ respectively indicate the concave and convex degrees of the gain area and the loss area of the value function, reflecting a senior care facility's different risk attitudes towards gain and loss: The bigger $\alpha$ and $\beta$ are, the more likely the senior care facility is to take risks; $\lambda$ represents the degree of loss avoidance of the senior care facility: The bigger $\lambda$ is, to a great degree the senior care facility avoids losses.

For the caregivers, if the prospective value $V\left(C_{1}\right)$ of "standard" caregiving behaviour $C_{1}$ is greater than the prospective value $V\left(C_{2}\right)$ of "non-standard" caregiving behaviour $C_{2}$, the caregivers will tend to choose "standard" caregiving behaviour; otherwise, they will prefer "non-standard" caregiving behaviour. It can be easily seen that $\Delta V_{C}$, the deviation of the caregivers' prospective value, can be used to judge how the caregivers will choose their caregiving behaviour. When $\Delta V_{C}>0$, the caregivers will choose "standard" caregiving behaviour, whereas when $\Delta V_{C} \leq 0$, they will choose "non-standard" caregiving behaviour.

-Proposition 1 The prospective value of the caregivers' choice of "standard" caregiving behaviour is negatively correlated with the cost of their risk responses $C_{C}$, negatively correlated with their risk loss sharing ratio $\beta$, and positively correlated with their risk loss discount factor $\gamma_{C}$.

Proof: Because

$$
\frac{\partial V\left(C_{1}\right)}{\partial C_{C}}=-W\left(P_{y}\right) V^{\prime}\left(E_{C}-C_{C}-T_{C}\right)-W\left(1-P_{y}\right) V^{\prime}\left(E_{C}-C_{C}+K_{M}-\left(1-\gamma_{C}\right) \beta L-T_{C}\right)<0
$$

$$
\begin{aligned}
& \begin{array}{l}
\frac{\partial V\left(C_{1}\right)}{\partial \beta}=-\left(1-\gamma_{C}\right) L W\left(1-P_{y}\right) V^{\prime}\left(E_{C}-C_{C}+K_{M}-\left(1-\gamma_{C}\right) \beta L\right. \\
\quad<0
\end{array} \\
& >0
\end{aligned}
$$

Proposition 1 stands. Proven.

Proposition 1 suggests that the greater the prospective value of the caregivers" choice of "standard" caregiving behaviour, the more willing they are to choose "standard" caregiving behaviour. Therefore, the cost of risk responses negatively impacts the caregivers' willingness to choose "standard" caregiving behaviour. Their risk loss sharing ratio negatively influences the caregivers' willingness to choose "standard" caregiving behaviour. And their risk loss discount factor 
positively impacts the caregivers' willingness to choose "standard" caregiving behaviour.

-Proposition 2 When $K_{M}<\left(1-\gamma_{C}\right) \beta L$, the prospective value of the caregivers' choice of "standard" caregiving behaviour is positively correlated with the facility managers' choice of "proactive" risk management behaviour, whereas when $K_{M}>\left(1-\gamma_{C}\right) \beta L$, the prospective value of the caregivers' choice of "standard" caregiving behaviour is negatively correlated with the facility managers' choice of "proactive" risk management behaviour.

Proof: It can be known from Formula (2) that

$$
\begin{aligned}
\frac{\partial V\left(C_{1}\right)}{\partial P_{y}} & =W^{\prime}\left(P_{y}\right) V\left(E_{C}-C_{C}-T_{C}\right)+W^{\prime}\left(1-P_{y}\right) V\left(E_{C}-C_{C}+K_{M}-\left(1-\gamma_{C}\right) \beta L-T_{C}\right) \\
& =\frac{k\left(P_{y}\right)^{k-1}\left(1-P_{y}\right)^{k-1}}{\left[\left(P_{y}\right)^{k}+\left(1-P_{y}\right)^{k}\right]^{2}}\left[V\left(E_{C}-C_{C}-T_{C}\right)-V\left(E_{C}-C_{C}+K_{M}-\left(1-\gamma_{C}\right) \beta L-T_{C}\right)\right] .
\end{aligned}
$$

Since the prospective value function $V(x)$ is a monotonically increasing function on $(-\infty,+\infty)$,

when $K_{M}-\left(1-\gamma_{C}\right) \beta L>0, V\left(E_{C}-C_{C}-T_{C}\right)-V\left(E_{C}-C_{C}+\right.$ $\left.K_{M}-\left(1-\gamma_{C}\right) \beta L-T_{C}\right)<0$, and therefore $\frac{\partial V\left(C_{1}\right)}{\partial P_{y}}<0$.

When $K_{M}-\left(1-\gamma_{C}\right) \beta L<0,\left(E_{C}-C_{C}-T_{C}\right)-V\left(E_{C}-C_{C}+\right.$ $\left.K_{M}-\left(1-\gamma_{C}\right) \beta L-T_{C}\right)>0$, and therefore $\frac{\partial V\left(C_{1}\right)}{\partial P_{y}}>0$. Proven.

Proposition 2 indicates that when the gain the caregivers receive from the government or industry regulators for choosing "standard" caregiving behaviour is greater than the risk loss they share, they might, driven by a speculative mentality, expect to benefit from the punishment on the managers' "passive" risk management behaviour. As a result, their perceived prospective value of providing "standard" caregiving behaviour will decrease, and their willingness for choosing "standard" caregiving behaviour might also reduce. In comparison, when the gain the caregivers receive from the government or industry regulators for choosing "standard" caregiving behaviour is less than the risk loss they share, their perceived prospective value of providing "standard" caregiving behaviour will increase, leading to their increased willingness to choose "standard" caregiving behaviour. Therefore, when the government and industry regulators formulate reward strategies for the caregivers, they need to bear in mind that higher reward does not necessarily lead to better results. Instead, they must limit the reward to a reasonable range so as to effectively motivate the caregivers to adopt "standard" caregiving behaviour.

$$
\begin{aligned}
\Delta V_{M}=V\left(M_{1}\right)-V\left(M_{2}\right)= & W\left(P_{x}\right)\left[V\left(E_{M}-C_{M}-T_{M}\right)-V\left(E_{M}-K_{M}-\left(1-\gamma_{C}\right)(1-\beta) L-T_{M}\right)\right] \\
& +W\left(1-P_{x}\right)\left[V\left(E_{M}-C_{M}+K_{C}-\left(1-\gamma_{M}\right)(1-\beta) L-T_{M}\right)-V\left(E_{M}-K_{M}-(1-\beta) L-T_{M}\right)\right]
\end{aligned}
$$


In Formulas (5) to (7), if $\pi_{C_{i},} M_{j}{ }^{M}-T_{M}>0$, then $V\left(\pi_{C_{i}}\right.$, $\left.M_{j}{ }^{M}\right)=\left(\pi_{C_{i},} M_{j}{ }^{M}-T_{M}\right)^{\alpha}$; and if $\pi_{C_{i},} M_{j}{ }^{M}-T_{M} \leq 0$, then $V$ $\left(\pi_{C_{i},} M_{j}{ }^{M}\right)=-\lambda\left(-\pi_{C_{i},} M_{j}{ }^{M}+T_{M}\right)^{\beta}$, and $i, j \in\{1,2\}$.

This study uses $\Delta V_{M}$, the deviation of the prospective value of the managers' different risk management behaviour, to judge how managers will make risk management decisions. When $\Delta V_{M}>0$, the prospective value $V\left(M_{1}\right)$ of "proactive" risk management behaviour $M_{1}$ is greater than the prospective value $V\left(M_{2}\right)$ of "passive" risk management behaviour $M_{2}$, in which case the managers will choose "proactive" risk management behaviour; in comparison, when $\Delta V_{M} \leq 0$, the prospective value $V\left(M_{1}\right)$ of "proactive" risk management behaviour $M_{1}$ is lower than the prospective value $V\left(M_{2}\right)$ of "passive" risk management behaviour $M_{2}$, in which case the managers will choose "passive" risk management behaviour.

-Proposition 3 The prospective value of the managers choice of "proactive" risk management behaviour is negatively correlated with their risk response $\operatorname{cost} C_{M}$, negatively correlated with their risk loss sharing ratio $\beta$, and positively correlated with their risk loss discount factor $\gamma_{M}$.

Proof: Because

$$
\begin{aligned}
\frac{\partial V\left(M_{1}\right)}{\partial C_{M}} & =-W\left(P_{x}\right) V^{\prime}\left(E_{M}-C_{M}-T_{M}\right) \\
& +W\left(1-P_{x}\right) V^{\prime}\left(E_{M}-C_{M}+K_{C}-\left(1-\gamma_{M}\right)(1-\beta) L-T_{M}\right)<0 \\
\frac{\partial V\left(M_{1}\right)}{\partial(1-\beta)}= & -\left(1-\gamma_{M}\right) L W\left(1-P_{x}\right) V^{\prime}\left(E_{M}-C_{M}+K_{C}-\left(1-\gamma_{M}\right)(1-\beta) L-T_{M}\right)<0
\end{aligned}
$$

and

$\frac{\partial V\left(M_{1}\right)}{\partial \gamma_{M}}=(1-\beta) L W\left(1-P_{x}\right) V^{\prime}\left(E_{M}-C_{M}+K_{C}-\left(1-\gamma_{M}\right)(1-\beta) L-T_{M}\right)>0$

Proposition 3 stands. Proven.

Proposition 3 suggests that the greater the prospective value of the managers' choice of "proactive" risk management behaviour, the more willing they are to choose "proactive" risk management behaviour. Therefore, the risk response cost negatively impacts the managers' willingness to choose "proactive" risk management behaviour. The managers' risk loss sharing ratio negatively influences their willingness to choose "proactive" risk management behaviour. And the managers' loss discount factor positively impacts their willingness to choose "proactive" risk management behaviour.

-Proposition 4 When $K_{C}<\left(1-\gamma_{M}\right)(1-\beta) L$, the managers' willingness to choose "proactive" risk management behaviour is positively correlated with the caregivers' probability of choosing "standard" caregiving behaviour, whereas when $K_{C}>\left(1-\gamma_{M}\right)(1-\beta) L$, the managers' willingness to choose "proactive" risk management behaviour is negatively correlated with the caregivers' probability of choosing "standard" caregiving behaviour.

Proof: The process of proof is similar to that of Proposition 2. It can be easily proven that Proposition 4 stands.

It can be known from Proposition 4 that once the gain the managers receive from their choice of "proactive" risk management behaviour exceeds the risk loss they share, they might develop the speculative mentality of benefiting from the punishment on the caregivers' "non-standard" caregiving behaviour. As a result, their willingness to choose "proactive" risk management behaviour might reduce. In comparison, when the gain the managers receive from their choice of "proactive" risk management behaviour is less than the risk loss they share, their willingness to choose "proactive" risk management behaviour might increase.

Propositions 2 and 4 suggest that the government and industry regulators need to weigh and balance the pros and cons of the reward and punishment when formulating the reward and punishment mechanism for long-term care facilities. They must limit the reward and punishment within a proper range to truly give full play to the incentive and restrictive role of the optimal risk management behaviour on the staff in long-term care facilities.

\subsection{The decision-making model for risk responses under centralized decisions}

To analyze the optimal strategies for the risk responses of long-term care facilities and their constraints, this section compare the caregivers' two strategies and the facility managers' two strategies respectively based on the matrix of the risk responses of the caregivers and the managers, and underlines the best strategies. In the end, the strategy profile with all the strategies underlined is the equilibrium.

For the caregivers, if $C_{C}<K_{C}+\left(1-\gamma_{M}\right) \beta L$, then $\pi_{C_{1},} M_{1}{ }^{C}$ $=E_{C}-C_{C}>\pi_{C_{2},} M_{1}{ }^{C}=E_{C}-K_{C}-\left(1-\gamma_{M}\right) \beta L$. If $C_{C}<K_{C}+$ $K_{M}+\gamma_{C} \beta L$, then $\pi_{C_{1},} M_{2}{ }^{C}=E_{C}-C_{C}+K_{M}-\left(1-\gamma_{C}\right) \beta L>$ $\pi_{C_{2},} M_{2}{ }^{C}=E_{C}-K_{C}-\beta L$. Therefore, when the cost for the caregivers to engage in "standard" caregiving behaviour $C_{C}$ $<\min \left\{K_{C}+\left(1-\gamma_{M}\right) \beta L, K_{C}+K_{M}+\gamma_{C} \beta L\right\}$, "standard" caregiving behaviour $C_{1}$ is caregivers' dominant strategy.

For the facility managers, if $C_{M}<K_{M}+\left(1-\gamma_{C}\right)(1-\beta) L$, then $\pi_{C_{1},} M_{1}{ }^{M}=E_{M}-C_{M}>\pi_{C_{1},} M_{2}{ }^{M}=E_{M}-K_{M}-\left(1-\gamma_{C}\right)$ $(1-\beta) L$. If $C_{M}<K_{C}+K_{M}+\gamma_{M}(1-\beta) L$, then $\pi_{C_{2},} M_{1}{ }^{M}=$ $E_{M}-C_{M}+K_{C}-\left(1-\gamma_{M}\right)(1-\beta) L>\pi_{C_{2},} M_{2}{ }^{M}=E_{M}-K_{M}-$ $(1-\beta) L$. Therefore, when the cost for the managers to engage in "proactive" risk management behaviour $C_{M}<\min \left\{K_{M}+\right.$ $\left.\left(1-\gamma_{C}\right)(1-\beta) L, K_{C}+K_{M}+\gamma_{M}(1-\beta) L\right\}$, "proactive" risk management behaviour $M_{1}$ is the managers' dominant strategy. 
The optimal state of risk management in long-term care facilities is one in which both the facility managers and the caregivers attach enough importance to and actively engage in COVID-19 risk management activities and "standard" caregiving behaviour respectively to minimize COVID-19 risks and related risk loss for the facilities. Therefore, if the cost of the risk responses of both the caregivers and the managers in long-term care facilities meets the following two conditions,

$$
\begin{aligned}
& C_{C}<\min \left\{K_{C}+\left(1-\gamma_{M}\right) \beta L, K_{C}+K_{M}+\gamma_{C} \beta L\right\} \\
& C_{M}<\min \left\{K_{M}+\left(1-\gamma_{C}\right)(1-\beta) L, K_{C}+K_{M}+\gamma_{M}(1-\beta) L\right\}
\end{aligned}
$$

the system will converge to the equilibrium strategy $\left(C_{1}, M_{1}\right)$ (see Table 3). At this point, the facility managers attach importance to and proactively carry out COVID-19 risk management activities; the caregivers proactively engage in "standard" caregiving behaviour; and the COVID-19 risk intensity in long-term care facilities is minimized, so is the risk loss.

The $C_{C}$ constraints indicate that, in general, the cost for the caregivers to proactively engage in "standard" caregiving behaviour should be lower than their perceived value of the punishment on their engagement in "non-standard" caregiving behaviour, their perceived value of their gain from the managers' "passive" COVID-19 risk management behaviour, and their perceived value of the risk loss reduction. It should also be lower than their perceived value of the risk loss reduced by the managers" "proactive" COVID-19 risk management behaviour.

The $C_{M}$ constraints suggest that, in general, the cost for the long-term care facilities managers to proactively engage in COVID-19 risk management should be lower than their perceived value of the punishment on their engagement in "passive" risk management behaviour, their perceived value of the risk loss caused to long-term care facilities by the caregivers' "non-standard" caregiving behaviour, and their perceived value of COVID-19 risk loss reduction. Besides, it should not exceed their perceived value of the risk loss reduced by the caregivers' engagement in "standard" caregiving behaviour.

\section{Simulation analysis of the decision-making on risk responses}

In order to visualize the impact of such factors as industry personnel factors (the probability of risk response choices reflects the general characteristics of the risk responses of the industry personnel), risk response cost as well as risk loss incurred to the facilities on the risk response decisions of the caregivers and the managers, this section employs numerical simulation to simulate the evolution of the risk response decisions of the caregivers and the managers.

In the following simulation analysis, first, with reference to Gonzalez and Wu's $(1996,1999)$ [35, 36] setting of weight function, assume the parameter of the weight function $k=$ 0.61. And with reference to Kahneman and Tversky's (1992) [37] setting of the parameter of value function in their study, assume that $\alpha=0.89, \beta=0.92, \lambda=2.25$. Second, fix the values of the parameters as follows: $E_{C}=10, E_{M}=15$, $C_{C}=5, C_{M}=6, \gamma_{C}=0.4, \gamma_{M}=0.45, L=50, K_{C}=K_{M}=5$, $P_{x}=0.5, P_{y}=0.6, T_{C}=T_{M}=0$, (All these parameters are dimension-free. The dimensions of the parameters can be reasonably set according to the specific question.). Finally, when examining the change in one parameter (for example, the increase of $P_{x}$ from 0 to 1 ), fix the rest of the parameters as indicated above, and only analyze the impact of the said parameter on the variable in question (such as $V\left(C_{1}\right)$ ).

\subsection{The impact of the industry personnel on risk response decision-making}

Respectively set the variable variables of the model as $P_{y}$, the probability for the managers to choose "proactive" risk management behaviour (increase from 0 to 1 with a step size of $0.1)$ and $P_{x}$, the probability for the caregivers to choose "standard" caregiving behaviour (increase from 0 to 1 with a step size of 0.1). The simulation results are shown in Fig. 3. It can be seen from Fig. 3 that as $P_{y}$, the probability for the managers to choose "proactive" risk management behaviour, increases, the prospective value of the caregivers' "standard" and "nonstandard" caregiving behaviour will both increase, and the

\begin{tabular}{|c|c|c|}
\hline \multirow[t]{2}{*}{ Caregivers $(C)$} & \multicolumn{2}{|l|}{ Facility managers $(M)$} \\
\hline & $\begin{array}{l}\text { "Proactive" risk management } \\
\text { behaviour } M_{1}\end{array}$ & "Passive" risk management behaviour $M_{2}$ \\
\hline "Standard" caregiving behaviour $C_{1}$ & $\begin{array}{l}\pi_{C_{1},} M_{1}^{C}=E_{C}-C_{C} \\
\pi_{C_{1},} M_{1}^{M}=E_{M}-C_{M}\end{array}$ & $\begin{array}{l}\pi_{C_{1},} M_{2}{ }^{C}=E_{C}-C_{C}+K_{M}-\left(1-\gamma_{C}\right) \beta L \\
\pi_{C_{1},} M_{2}{ }^{M}=E_{M}-K_{M}-\left(1-\gamma_{C}\right)(1-\beta) L\end{array}$ \\
\hline "Non-standard" caregiving behaviour $C_{2}$ & $\begin{array}{l}\pi_{C_{2},} M_{1}{ }^{C}=E_{C}-K_{C}-\left(1-\gamma_{M}\right) \beta L \\
\pi_{C_{2},} M_{1}{ }^{M}=E_{M}-C_{M}+K_{C}-\left(1-\gamma_{M}\right)(1-\beta)\end{array}$ & $\begin{array}{l}\pi_{C_{2},} M_{2}{ }^{C}=E_{C}-K_{C}-\beta L \\
\pi_{C_{2},} M_{2}{ }^{M}=E_{M}-K_{M}-(1-\beta) L\end{array}$ \\
\hline
\end{tabular}

Table 3 The equilibrium strategy between the caregivers and the managers under centralized decisions. 

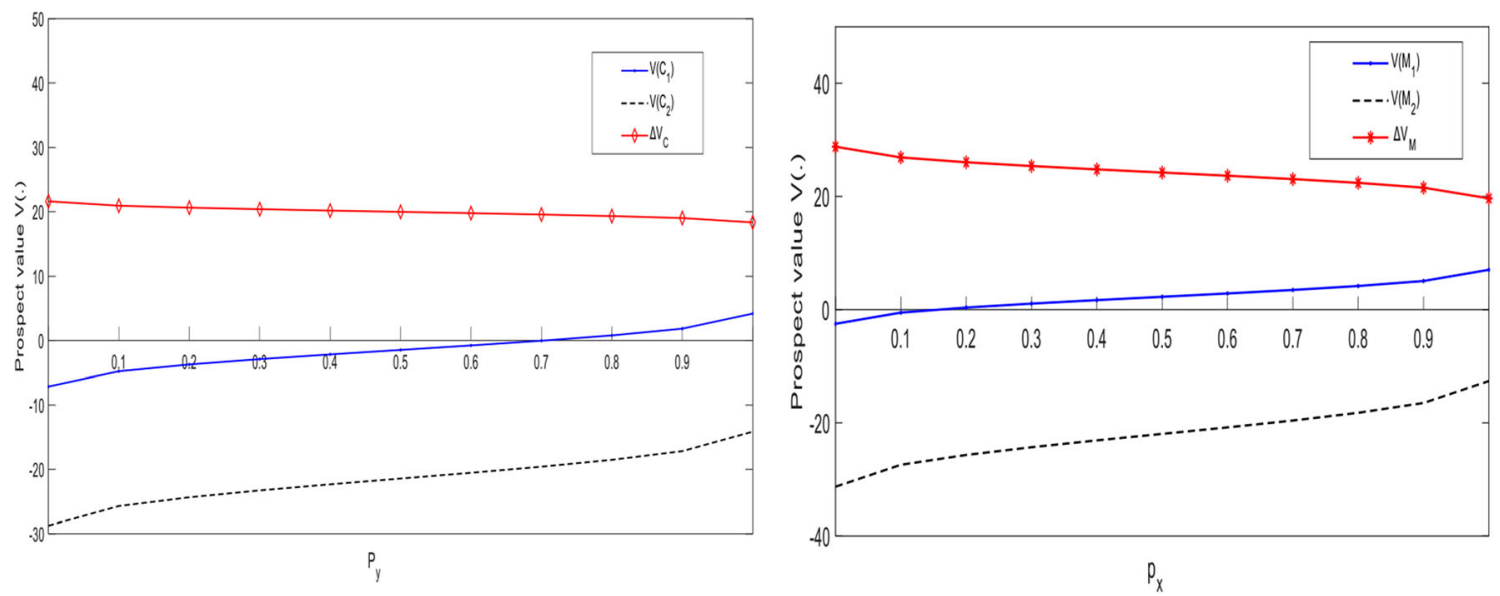

Fig. 3 The impact of risk response probabilities $P_{x}$ and $P_{y}$ on risk response decision-making

prospective value of the caregivers' "standard" caregiving behaviour is always greater than the prospective value of their "non-standard" caregiving behaviour. Similarly, it can be seen that the probability for the caregivers to choose "standard" caregiving behaviour is positively correlated with the managers' willingness to choose "proactive" risk management. In other words, industry personnel (the probability of risk response choices) have a positive impact on the risk response decision-making of the caregivers and the managers.

\subsection{The impact of management cost on risk response decision-making}

Respectively set the variable variables of the model as $C_{C}$, the cost of the caregivers' choice of "standard" caregiving behaviour (increase from 1 to 10 with a step size of 1 ) and $C_{M}$, the cost of the managers' choice of "proactive" risk management behaviour (increase from 1 to 10 with a step size of 1). The simulation results are shown in Fig. 4. It can be seen from Fig. 4 that as $C_{C}$, the cost of the caregivers' choice of "standard" caregiving behaviour, increases, the prospective value of the caregivers' "standard" caregiving behaviour gradually decreases, the prospective value of their "non-standard" caregiving behaviour remains unchanged (the prospective value is always negative), and the willingness for the caregivers to choose "standard" caregiving behaviour gradually reduces. However, because the prospective value of the caregivers' "standard" caregiving behaviour is always greater than the prospective value of their "non-standard" caregiving behaviour, choosing "standard" caregiving behaviour remains the optimal decision. Similarly, it can be seen that the greater the $C_{M}$, the cost of the managers' choice of "proactive" risk management behaviour, the smaller the prospective value of the managers' engagement in "proactive" risk management behaviour, and the lower their willingness to engage in "proactive" risk management. However, since the prospective value of the managers' "proactive" risk management is always greater than the prospective value of their "passive" risk management, choosing "proactive" risk management remains the optimal decision for the managers. In other words, the
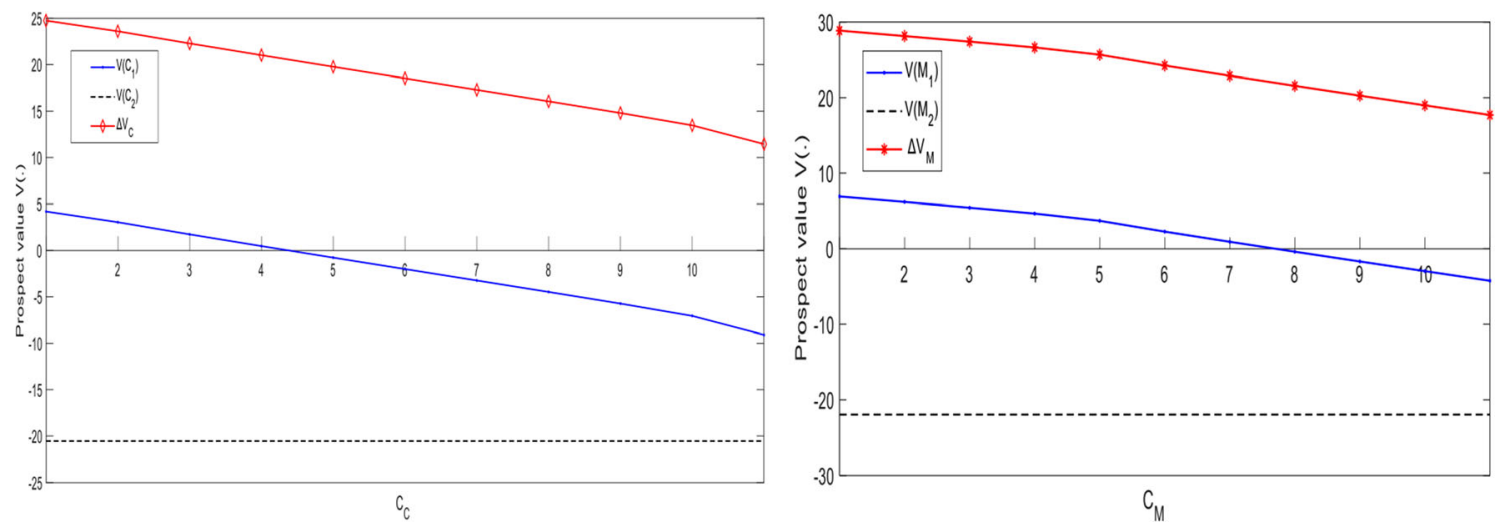

Fig. 4 The impact of risk management $\operatorname{cost} C_{C}$ and $C_{M}$ on risk response decision-making 
management cost of risk responses has a negative impact on the risk response decision-making of the caregivers and the managers.

\subsection{The impact of risk loss on risk response decisions}

First, respectively set the variable variables of the model as $\gamma_{C}$, the risk loss discount factor of the caregivers' choice of "standard" caregiving behaviour (increase from 0.1 to 1 with a step size of 0.1) and $\gamma_{M}$, the risk loss discount factor of the managers' choice of "proactive" risk management behaviour (increase from 0.1 to 1 with a step size of 0.1 ). The simulation results are shown in Fig. 5. Then, set the variable of the model as $L$, the risk loss of long-term care facilities (increase from 20 to 70 with a step size of 5). Afterwards, analyze the impact of the risk loss of long-term care facilities on the risk response decision-making of the caregivers and the managers. The simulation results are shown in Fig. 6.

It can be seen from Fig. 5 that as $\gamma_{C}$, the risk loss discount factor of the caregivers' choice of "standard" caregiving behaviour, increases, the prospective value of the caregivers' "standard" caregiving behaviour also increases, and the prospective value of their "non-standard" caregiving behaviour remains unchanged (the prospective value is negative), causing their willingness to choose "standard" caregiving behaviour to gradually increase. For the managers, the larger the $\gamma_{M}$, the risk loss discount factor of their choice of "proactive" risk management behaviour, the greater the prospective value of their engagement in "proactive" risk management behaviour, and correspondingly the stronger their willingness to engage in "proactive" risk management. In other words, risk loss discount factor has a positive impact on the risk response decision-making of the caregivers and the managers.

It can be seen from Fig. 6 that the larger the $L$, the risk loss of long-term care facilities, the smaller the prospective values of both the caregivers" "standard" caregiving behaviour and their "non-standard" caregiving behaviour. Nevertheless, since the prospective value of the caregivers" "non-standard" caregiving behaviour reduces faster, their willingness to choose "standard" caregiving behaviour still gradually increases. A similar conclusion can be drawn for the managers. Therefore, both risk loss discount factor and the risk loss of long-term care facilities have a positive impact on the risk response decision-making of the caregivers and the managers.

\section{Risk management and control strategies based on the prospect theory}

(1) Noel et al. [38] found in their research that risk perception is the subjective judgment people make about the characteristics and severity of a particular risk and that it is correlated with individual behaviour. The two-factor theory of risk suggests that risk perception involves value judgments about the subjective probability of the occurrence of decision consequences and the severity of the consequences of wrong decisions. The lower the level of risk perception, the greater the tendency to ignore the risk instead of proactively taking precautions to reduce loss when faced with a potential risk threat. On the contrary, the higher the level of risk perception, the greater the tendency to choose to proactively avoid COVID19 risks or take precautions to reduce loss caused by COVID19 risks when faced with potential COVID-19 risks. Factors influencing the perception of COVID-19 risks include the perception bias towards COVID-19 risks and the acceptable level of risks.

To enable the caregivers and the managers of long-term care facilities to converge to the equilibrium strategy $\left(C_{1}\right.$, $M_{1}$ )with the largest probability, it is necessary to have the two conditions in Formulas (8) and (9) met. However, the existence of risk perception differences and prospect theory effect may make it difficult for the system to converge to the equilibrium strategy $\left(C_{1}, M_{1}\right)$.
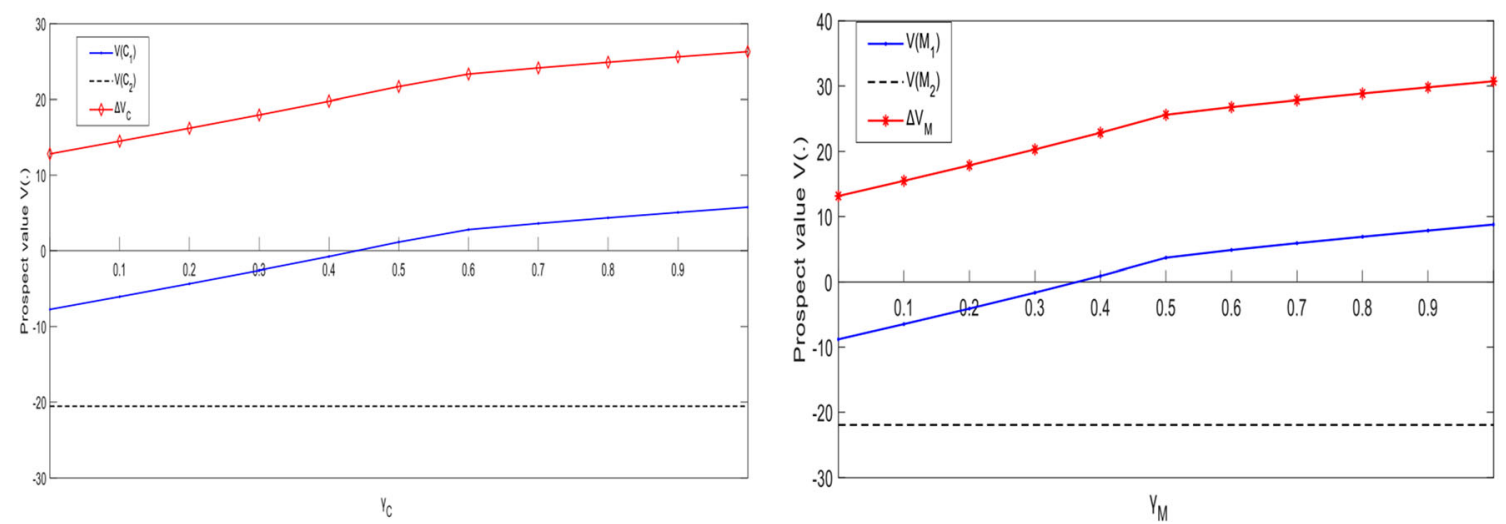

Fig. 5 The impact of the risk loss discount factors $\gamma_{C}$ and $\gamma_{M}$ on risk response decision-making 


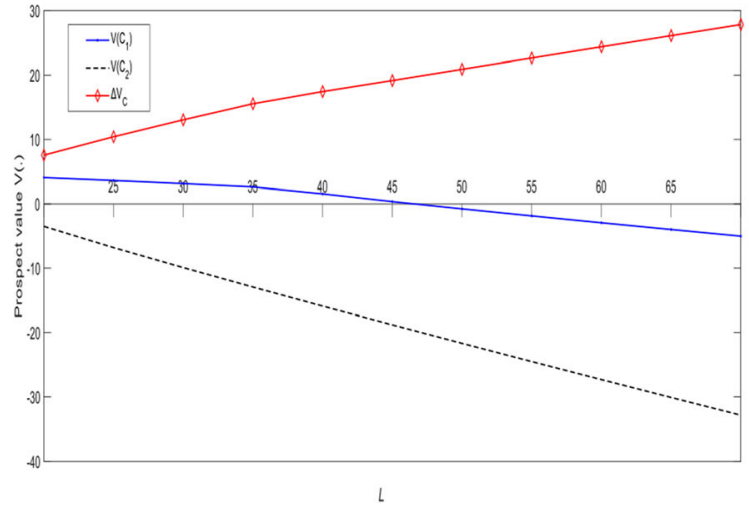

Fig. 6 The impact of the risk loss $L$ on risk response decision-making

The actual COVID-19 risk management cost is less than the perceived COVID-19 risk management cost. In other words, $V\left(C_{C}\right) \geq C_{C}$ and $V\left(C_{M}\right) \geq C_{M}$. When the facility managers or the caregivers choose to proactively carry out COVID-19 risk management, the probability of occurrence of the said behaviour $p_{x}=p_{y}=1$ According to the prospect theory, it can be known that:

$$
\begin{aligned}
V\left(C_{C}\right) & =W\left(p_{x}\right) V\left(C_{C}\right)+W\left(1-p_{x}\right) V(0) \\
& =\mathrm{W}(1) V\left(C_{C}\right)+\mathrm{W}(0) V(0) \geq C_{C} \\
V\left(C_{M}\right) & =W\left(p_{y}\right) V\left(C_{M}\right)+W\left(1-p_{y}\right) V(0) \\
& =\mathrm{W}(1) V\left(C_{M}\right)+\mathrm{W}(0) V(0) \geq C_{M}
\end{aligned}
$$

In the above formulas, $C_{C}$ and $C_{M}$ respectively refer to the actual cost for the facility managers and the caregivers to proactively carry out risk management.

(2) The facility managers and the caregivers are prone to a fluke mentality and optimism bias when making judgments about the value of strategy choices. Optimism bias manifests as a form of unrealistic optimism. People are more prone to optimism bias when considering their own risks, believing that they are less likely to experience negative events and more likely to experience positive events than ordinary people [39], and they tend to believe that things will turn out well. In general, optimism bias lowers the level of risk perception among managers and staff, thus causing them to underestimate the existence of COVID-19 risks, reduce problemsolving efforts, and reduce the willingness to prevent COVID-19 risk. The optimism biases of the facility managers and caregivers cause them to hope for occasional nonoccurrence of risk accidents and loss and be more prone to underestimating the probability of occurrence of risky events and the probability of punishment that may result from passive risk management practices, while knowing that passive risk management may result in risk loss. Besides, according to the

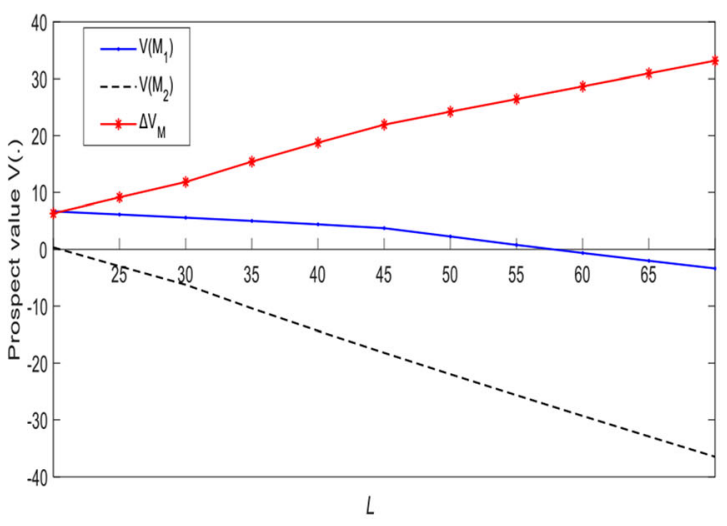

prospect theory, except for events of minimal probability, weighting function has the characteristic of $W\left(p_{i}\right) \leq p_{i}$. And when $\Delta \varpi_{i}>0, V\left(\Delta \varpi_{i}\right)$ has the features of a convex function. It can thus be seen that $W\left(p_{1}\right) \leq p_{1}, W\left(p_{2}\right) \leq p_{2}, W\left(p_{3}\right) \leq$ $p_{3}, V\left(d_{C}\right) \leq d_{C}, V\left(d_{M}\right) \leq d_{M}$ and $V(l) \leq l$. Specifically, $P_{1}$ refers to the objective probability of occurrence of COVID-19 risk accidents: $P_{2}$ and $P_{3}$ respectively refer to the objective probability for facility managers and that for caregivers to be punished due to the occurrence of COVID-19 risk; $d_{C}$ and $d_{M}$ refer to the actual punishment cost paid by the facility managers and caregivers respectively for adopting passive risk management strategies; and $l$ represents the actual loss caused by the occurrence of COVID-19 risk. Thus:

$$
\begin{aligned}
& L=W\left(p_{1}\right) V(l)+W\left(1-p_{1}\right) \mathrm{V}(0)=W\left(p_{1}\right) V(l) \leq p_{1} l \\
& D_{C}=W\left(p_{2}\right) V\left(d_{C}\right)+W\left(1-p_{2}\right) \mathrm{V}(0)=W\left(p_{2}\right) V\left(d_{C}\right) \leq p_{2} d_{C} \\
& D_{M}=W\left(p_{3}\right) V\left(d_{M}\right)+W\left(1-p_{3}\right) \mathrm{V}(0) \\
& \quad=W\left(p_{3}\right) V\left(d_{M}\right) \leq p_{3} d_{M}
\end{aligned}
$$

(3) According to the reflection effect put forward in the prospect theory, people's preferences for gains and losses are asymmetric. And when faced with the prospect of gain (or profits), people tend to be risk averse, whereas when faced with the prospect of possible loss, they tend to be risk seeking. When faced with the certainty of loss, the managers and the caregivers in long-term care facilities, as decision-makers with bounded rationality, tend to have a high appetite for risks. Specifically, they prefer to give up the certain cost incurred by a proactive risk management strategy in favour of taking the risk of choosing a passive risk management strategy and facing the uncertainty of loss and punishment caused by risk accidents, making it difficult for the system to converge at the equilibrium strategy $\left(C_{1}, M_{1}\right)$. As a result, the cost of COVID19 risks of the facility managers and caregivers tends to be overestimated and the risk loss underestimated, causing $C_{C}$ and $C_{M}$ to be larger than necessary while $D_{C}, D_{M}$ and L 
smaller than needed, and both parties have the tendency to take the risk of choosing passive risk management strategies. In reality, there are inevitable reasons as to why the facility managers and caregivers attach insufficient importance to risk management and adopt passive risk management strategies. When long-term care facilities meet the above conditions, the optimal equilibrium strategy $\left(C_{1}, M_{1}\right)$ will be realized, where both the facility managers and the caregivers attach important to and proactively carry out risk management activities or engage in "standard" caregiving behaviour, thereby reducing the probability of occurrence of COVID-19 risks and minimize the loss incurred by COVID-19 risks to long-term care facilities.

\section{Conclusions}

This study uses the prospect theory to establish the decisionmaking models for the different risk responses of the caregivers and the managers, formulates the optimal strategies by comparing the prospective value of their gain from different risk responses. Furthermore, the influences of factors such as the stakeholders' behaviour, risk management cost, risk loss and external regulation on the two parties' risk response decisions are discussed. Finally, the constraints for the caregivers and the managers to achieve the optimal risk management strategies are analyzed from the perspective of long-term care facilities. This study reveals the internal mechanism of risk behavior decision-making by the caregivers and managers in long-term care facilities, deepens the cognition of COVID19 risks by caregivers and managers, and contributes to the transformation, decomposition and effective prevention and control of COVID-19 risks in long-term care facilities.

Abbreviations COVID-19, coronavirus disease 2019; WHO, World Health Organization; PHEIC, Public Health Emergency of International Concern; China CDC, Chinese Center for Disease Control and Prevention; CFR, case fatality rate; FMEA, Failure mode effects analysis

Acknowledgements The authors acknowledge the National Natural Science Foundation of China (Grant: 71871147), the National Natural Science Foundation of China (Grant: 71701166), the National Natural Science Foundation of China (Grant: 71671144), the National Natural Science Foundation of China (Grant: 71271043), the Science and Technology Department of Sichuan Province Project (Grant: 2018ZR0201 \& 21YYJC2873), Chengdu Philosophy and Social Science Project (Grant: YY0920200643), and West China Nursing Discipline Development Special Fund Project, SichuanUniversity(Grant: HXHL20013).

\section{Declarations}

-Conflict of interest The authors declare no conflict of interest.

\section{References}

1. World Health Organization (2020) WHO Coronavirus Disease (COVID-19) Dashboard, World Health Organization, Geneva

2. Read JM, Bridgen JRE, Cummings DAT (2020) Novel coronavirus 2019-nCoV: early estimation of epidemiological parameters and epidemic predictions, MedRxiv

3. Lai J, Ma S, Wang Y (2020) Factors associated with mental health outcomes among health care workers exposed to coronavirus disease 2019. JAMA Netw Open 3(3):1-12

4. World Health Organization. Statement on the second meeting of the International Health Regulations (2005) Emergency Committee regarding the outbreak of novel coronavirus (2019-nCoV). World Health Organization, p 2020

5. Read JM, Bridgen JRE, Cummings DAT (2020) Novel coronavirus 2019-nCoV: early estimation of epidemiological parameters and epidemic predictions, MedRxiv

6. Adhikari S (2020) Pantaleo N P, Feldman J M, Ogedegbe O, Thorpe L, Troxel a B, assessment of community-level disparities in coronavirus disease 2019 (COVID-19) infections and deaths in large US metropolitan areas. JAMA Netw Open 3(7):1-4

7. Matthew C, Danielle I, Karen Y et al (2020) More than $40 \%$ of U.S. coronavirus deaths are linked to nursing homes. The New York Times

8. De L, Trabucchi M (2020) COVID-19 and the fears of Italian senior citizens. Int J Environ Res Public Health 17:3572

9. De Falco I, De Pietro G, Sannino G (2020) Evaluation of artificial intelligence techniques for the classification of different activities of daily living and falls. Neural Comput \& Applic 32:747-758

10. Sion K, Verbeek H, Aarts S (2020) The validity of connecting conversations: a narrative method to assess experienced quality of Care in Nursing Homes from the Resident's perspective. Int $\mathbf{J}$ Environ Res Public Health 17:5100

11. Awua J, Mensah J (2019) K, Krafona K, psychosocial, cognitive, and behaviour after effects of traumatic brain injury: perspectives of survivors and caregivers in Ghana. Journal of Psychosocial Rehabilitation and Mental Health 6:121-130

12. Trevino P, Green A, Middaugh D (2018) Nursing perception of risk in common nursing practice situations. Journal of Healthcare Risk Management 37(3):19-28

13. Farokhzadian J (2018) Nayeri N D, Borhani F, the long way ahead to achieve an effective patient safety culture: challenges perceived by nurses. BMC Health Serv Res 18(1):1-13

14. Fathollahi-Fard AM, Hajiaghaei-Keshteli M, Mirjalili S (2020) A set of efficient heuristics for a home healthcare problem. Neural Comput \& Applic 32:6185-6205

15. Sun XM, Ding Y, Wang H, Xu FL (2017) The development and application effect of inpatient care risk assessment early warning monitoring biography reporting system. Chinese Nursing Management 17:378-382

16. Lee SH, Kim HS (2017) Exercise interventions for preventing falls among older people in care facilities: A meta-analysis. Worldviews on Evidence-Based Nursing 14(1):74-80

17. Ogarek JA, McCreedy EM, Thomas KS (2018) Minimum data set changes in health, end-stage disease and symptoms and signs scale: a revised measure to predict mortality in nursing home residents. Journal of the American Geriatrics Society 66(5):976-981

18. Bielicki JA, Duval X, Gobat N (2020) Monitoring approaches for health-care workers during the COVID-19 pandemic. The Lancet Infectious Diseases 7(23):61-67

19. Shaw BH, Borrel D, Sabbaghan K (2019) Relationships between orthostatic hypotension, frailty, falling and mortality in elderly care home residents. BMC geriatrics 19(1):1-14 
20. Pivodic L, Smets T, Van den Noortgate N (2018) Quality of dying and quality of end-of-life care of nursing home residents in six countries: an epidemiological study. Palliat Med 32(10):1584-1595

21. Gubareva M (2018) Borges M R, rethinking economic capital management through the integrated derivative-based treatment of interest rate and credit risk. Ann Oper Res 266(1):71-100

22. Chiang CY (2014) A resident's behaviour simulation model for nursing home healthcare service. Biomed Mater Eng 24:69-75

23. McGilton KS, Escrig-Pinol A, Gordon A (2020) Uncovering the devaluation of nursing home staff during COVID-19: are we fuelling the next health care crisis? J Am Med Dir Assoc 21(7):962-965

24. Cheng L, Cui Y, Chen Q (2020) Paediatric nurses' general selfefficacy, perceived organizational support and perceived professional benefits from class A tertiary hospitals in Jilin province of China: the mediating effect of nursing practice environment. BMC Health Serv Res 20(1):1-9

25. Beck ER, McIlfatrick S, Hasson F (2017) Nursing home manager's knowledge, attitudes and beliefs about advance care planning for people with dementia in long-term care settings: a cross-sectional survey. Journal of Clinical Nursing 26(17):2633-2645

26. Li HY, Xin X, Liu T, Li JX (2015) The status quo and thinking of the problem of elder abuse in social aged care institutions. Chin J Gerontol 21:4846-4848

27. Gupta P, McClatchey R, Caleb-Solly P (2020) Tracking changes in user activity from unlabelled smart home sensor data using unsupervised learning methods. Neural Comput \& Applic 32:1235112362

28. Tang Y, Xu S, Li N, Sun H (2017) Y, insights and analysis on nurse's multiple-sites practice. Chin J Nurs 52:119-122

29. Kudo Y, Toyoda T, Terao R (2019) Job satisfaction and intention to remain on the job among Japanese nursing assistants. Journal of Rural Medicine 14(2):181-190
30. Shi Y, Cui X, Li D (2015) Discrete-time behavioural portfolio selection under cumulative prospect theory. $\mathrm{J}$ of Economica Dynamics \& Control 61:283-302

31. Gonzalez R, Wu G (1999) On the shape of the probability weighting function. Cogn Psychol 38:129-166

32. Zhao Z (2018) B, man Q P, evolutionary game analysis of risk management behaviour of major infrastructure projects based on prospect theory. Journal of Systems \& Management 27:110-117

33. Artime Ríos E, Suárez Sánchez A, Sánchez Lasheras F et al (2020) Genetic algorithm based on support vector machines for computer vision syndrome classification in health personnel. Neural Comput \& Applic 32:1239-1248

34. Gao K, Sun L, Yang Y (2021) Cumulative prospect theory coupled with multi-attribute decision making for modeling travel behavior. Transp Res A Policy Pract 148:1-21

35. Wang L, Zhang ZX, Wang YM (2015) A prospect theory-based interval dynamic reference point method for emergency decision making. Expert Syst Appl 42:9379-9388

36. Gonzalez R, Wu G (1996) Curvature of the probability weighting function. Manag Sci 42:1676-1690

37. Kahneman D, Tversky A (1992) Advances in prospect theory: cumulative representation of uncertainty. J Risk Uncertain 5:297-323

38. Noel T, Brewer N, Gretchen B, Frederick X, Gibbons N, Meg G (2007) C, Kevin D, meta-analysis of the relationship between risk perception and health behaviour: the example of vaccination. Health Psychol 26:136-145

39. Dolinski D, Dolinska B, Zmaczynska-Witek B (2020) Unrealistic optimism in the time of coronavirus pandemic: may it help to kill, if so-whom: disease or the person? J Clin Med 9(5):1464

Publisher's note Springer Nature remains neutral with regard to jurisdictional claims in published maps and institutional affiliations. 